\title{
Developing a diversification
} strategy of non-agricultural activities on farms using system dynamics modelling: a case study of Slovenia

\author{
Maja Žibert
}

Faculty of Agriculture and Life Science, University of Maribor, Maribor, Slovenia

Boris Prevolšek

Faculty of Tourism, University of Maribor, Maribor, Slovenia

Karmen Pažek

Faculty of Agriculture and Life Science, University of Maribor, Maribor, Slovenia

Crtomir Rozman

Faculty of Agriculture and Life Science, University of Maribor, Maribor, Slovenia and

University of Maribor, Maribor, Slovenia, and

Andrej Škraba

Faculty of Organisational Science, University of Maribor, Maribor, Slovenia

\begin{abstract}
Purpose - This paper aims to analyse the main variables and causal relationships in the system structure of the diversification of non-agricultural activities on agricultural holdings using system dynamics (SD) modelling. The SD model aims to simulate depictions of the behaviour of the real system while testing the effects of alternative decisions over time.

Design/methodology/approach - An SD methodology was chosen to model diversification in farm tourism. Findings - A system approach increases the authors' understanding of the transition of agricultural holdings to farm tourism. The results indicate that the transition to farm tourism depends on the level of tourism development in a certain area. The system is influenced by subsidies allocated by authorities to expand primary agricultural activities. The model describes a situation in which the tourism and agricultural industries have been affected by the COVID-19 pandemic.

Research limitations/implications - The research is limited by the small set of available data due to the limited number of farms in Slovenia. One major problem is the difference in statistical data on the same activity collected from different institutions in Slovenia.

Practical implications - The paper includes implications for understanding the transition process to farm tourism, allowing policymakers to experiment with subsidies and promotion to explore the efficacy and efficiency of proposed policies.

Originality/value - This study provides a structured, systemic view of the diversification of non-agricultural activities on agricultural holdings, where the simulation results are a reliable reflection of the behaviour of the actual system being modelled.
\end{abstract}

Keywords System dynamics, Modelling, Simulation, Diversification, Farm tourism, Farm policy, Slovenia, Simulation scenarios

Paper type Research paper

(C) Maja Žibert, Boris Prevolšek, Karmen Pažek, Črtomir Rozman and Andrej Škraba. Published by Emerald Publishing Limited. This article is published under the Creative Commons Attribution (CC BY 4.0) licence. Anyone may reproduce, distribute, translate and create derivative works of this article (for both commercial and non-commercial purposes), subject to full attribution to the original publication and authors. The full terms of this licence may be seen at http://creativecommons.org/licences/by/4.0/legalcode

The research has been founded by Slovene research agency program P4-0022.

Developing a diversification strategy
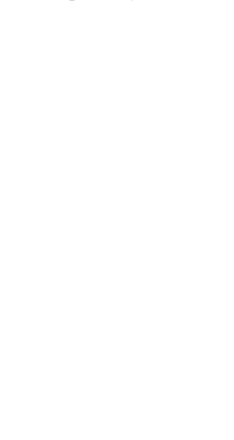
$\mathrm{K}$

51,13

\section{Introduction}

Tourism is a globally important industry (Sinclair-Maragh and Gursoy, 2016; Martins et al., 2017; Romão et al., 2018) that contributes significantly to the world's gross domestic product (GDP). It is a complex system with many interactions between sectors, stakeholders and managers, and great diversity of interests in the management and use of services (Mai and Smith, 2018; Sedarati et al., 2019).

The combination of tourism and economic activities in rural areas is called "agritourism" (Marsat et al., 2013). Agriculture is an integral part of national economies and a contributing factor to population growth. Locally, rural activities play a prominent role in the everyday lives of citizens In addition to contributing to the national and global food supply, the countryside provides an environment for relaxation and recreation. Indeed, farm tourism is not a new phenomenon (Busby and Rendle, 2000). According to Dernoi (1983), the importance of farm tourism has increased from the point of view of both tourism and the agricultural economy, which represents an important additional source of income for farms. Today, thanks to new technologies that can monitor consumer habits and statistics daily, it is easier to plan the development of this sector using, for instance, system dynamics (SD) methodologies (Forrester, 1994; Sterman, 2000; Rahmandad and Sterman, 2012).

In many countries and regions, farm tourism has developed very successfully. For example, in Italy, the number of registered tourist farms in 2015 had increased by $60 \%$ (National Institute of Statistics, 2015) compared to the previous decade. In Austria (Federal Ministry for Agriculture and Forestry, Environment and Water, 2015), 6\% of all farms offer tourism as a diversified activity. There is also a high percentage of tourist farms in the Alpine region of Germany: as many as $20 \%$ of all the farms in the area are involved in tourism, in addition to their primary activity (StMELF, 2015). Trends in the growth of accommodation facilities on tourist farms have also been seen in Slovenia. Different statistics have been recorded by different institutions, all reporting growth in the sector (Statistical Office of the Republic of Slovenia [SORS], 2018; Slovenian Business Register [AJPES], 2020).

Studying the development of rural tourism and other related activities requires insight into and understanding of the complex dynamics of agricultural and tourism development systems on the national and local levels. To plan for the future development of rural tourism, there is a clear need for modelling approaches that ensure decision support at the policymaking level (Žibert et al., 2019).

The paper is organised as follows. First, we describe the main problem with the related circumstances. Then, the development of the SD model is described. Based on main states, flows and feedback loops, a mathematical model is developed. In the scenario generation section, scenarios are presented with the developed SD model and evaluated. We conclude with a description of the study's limitations, main findings and proposals for further research.

\section{Literature overview}

Agricultural holdings gain an additional source of income by diversifying their activities. This source of income depends on how interesting the activities are for the market, the number of sources or raw materials, and the ambition of the members of the agricultural holding (Kerma et al., 2014; Pažek and Rozman, 2010; Potočnik Slavič, 2010). Tourism is one of several activities believed to be an efficient accelerator of development in the countryside. De Rosa et al. (2019), Huang et al. (2016), Cassel and Pettersson (2015) and Crumley (2010) proposed tourism as a possible answer to the economic challenges of rural areas.

\subsection{Study of agricultural systems}

Bontkes and van Keulen (2003) argue that the study of agricultural systems requires nonlinear dynamic models that allow the system to be simulated in a qualitative way, based 
on a description of the underlying processes. Costanza (1997) and Bontkes and van Keulen (2003) assert that in the case of research on agricultural systems, the use of nonlinear research dynamic models is necessary. Consequently, SD is one of the possible approaches. These models are based on descriptions of the basic processes. In addition, they allow the system to be simulated in a quantitative manner. We must be able to predict the effects of the policy (Adesina et al., 2000) and evaluate the efficiency of the models (Tzouvelekas et al., 2001) in order to facilitate strategic decision-making.

In modelling the processes of diversification of non-agricultural activities on farms, a broader review of the conditions and attributes is necessary. This includes the increased use of production capabilities and more rational use of natural, human and financial resources on a farm, all with the objective of seeking additional sources of income for an agricultural household. In the case of farm tourism as a method of diversification, environmental, social, sociological-cultural and economic factors are not negligible (Žibert et al., 2019).

High investment costs can be considered a negative aspect of the development of agricultural tourism (Sharpley, 2002). At the same time, there is no guarantee that investment costs will be recouped. Countries often provide investment support in setting up or further developing certain activities. However, farmers often encounter bureaucratic difficulties when seeking subsidies. Therefore, support services are an essential source of assistance (Arroyo et al., 2013; Kheiri and Nasihatkon, 2016; Su et al., 2019).

Another important factor in establishing subsidiary activity (tourism) on farms is the environment. Not every environment is suitable for tourism development. Suitability is shaped by infrastructural capacities and natural resources and attractions. A suggested by Gannon (1994), accommodation capacity alone does not meet the demand for the service.

When modelling the systems that include diversification activities to non-agricultural activities in the field of tourism, it is necessary to address two attributes: marketing and quality. Individual farms often lack the skills and resources needed for the efficient marketing of the activity (Embacher, 1994). Zasada and Piorr (2015) and Dubois et al. (2017) discuss the importance of tourism marketing in agricultural households. The latter stresses that, in the promotion of the activity, a proportionate interdepartmental image is necessary to provide an overview of what defines tourism in the countryside.

There is often a disconnect between the reality and the expectations of the interested developmental stakeholders. Regardless, when modelling SD, we must consider system limitations and our limited knowledge of the environment creation process (Sterman, 2000). Studies have shown that tourism as a non-agricultural activity on a farm represents not only economic benefits but also important non-economic benefits (Tew and Barbieri, 2012). Cunha et al. (2018) address the importance of family connections, personal pursuits and marketing opportunities as common non-economic benefits of farm and rural tourism.

Also, in Slovenia it is necessary to develop a methodological approach to evaluate developmental policies related to the spread of non-agricultural activities on farms and in the countryside and current practices. The factors that influence diversification change very rapidly, affected by exceptionally rapid global technological progress, the population trends in everyday life and tourism and travel development opportunities. This is particularly true in the case of the COVID-19 pandemic.

Sedarati et al. (2019) discuss the widespread use of SD in the tourism sector in different fields, including the attractions sector, adventure and outdoor recreation sector, transportation sector, accommodation sector, event sector, as well as multisector applications. Sedarati (2015) published a study proving the extent of SD in tourism in as many as 369 scientific papers. Johnson et al. (2008) describe the development of the TOPMARD model (Towards Policy Model of Multifunctional Agriculture and Rural Development). With the help of this model, policies have been modelled to better understand rural areas' agricultural, environmental, economic and social conditions. The model has also
Developing a diversification strategy 
$\mathrm{K}$

51,13

been used in the field of rural tourism development. Lazanski and Kljajić (2006) illustrated how tourism as a discipline can lead to the design and simulation of models through frameworks (Forrester, 1994). They also described the breadth of the sector considering the diversity of the economic, environmental and social dimensions. Further research has connected the field to agritourism (Jakulin, 2016).

A similar study about the diversification of non-agricultural activities using a systems approach was conducted by Žibert et al. (2020). Bastan et al. (2018) explored the transformation of agriculture through systemic dynamics. Bontkes and van Keulen (2003) reviewed the modelling approaches used to support decision-making related to the socioeconomic benefits of sustainable development, which can be understood as a beneficial concept for the agricultural community. Boorsma (1990) offers insight into the modelling of decision-making processes on the basis of the rules of decision-making. However, Dent et al. (1995) questioned the appropriateness of such normative models, which represent decision-making on an individual level.

The study of the diversification of non-agricultural activities on agricultural holdings, as the main object of this paper, is a distinct continuous-time problem. The study of the transitions of agricultural holdings to tourist farms also involves nonlinear representation. Therefore, the use of an SD methodology is appropriate for the chosen topic.

In this paper, a model of the diversification of non-agricultural activities based on the principles of SD in Slovenia is presented. The key variables that influence the dynamics of transformation are defined. The results may help formulate developmental policies that achieve the strategic goals of rural development (revitalisation).

\section{Methodology}

Based on the literature review, we selected SD modelling as a suitable methodological approach to the observed problem. There are five important steps to problem-solving in the SD modelling process: (1) identifying and defining the problem by formulating a dynamic hypothesis, (2) formulating a simulation model (by mapping a causal loop diagram), (3) developing a mathematical model, (4) testing the model and policy design, and (5) evaluating the model and policy design (Sterman, 2000). These steps are similar to those of the system approach.

The concept of SD is based on concepts related to the modelling of industrial dynamics created by Forrester in 1950. According to Ahmadvand et al. (2013) and Rozman et al. (2013), $\mathrm{SD}$ methodology is an effective method for analysing a system through simulation. The present study follows the steps of SD to develop a model of diversification of non-agricultural activities on agricultural holdings (related to farm tourism).

\subsection{Defining the problem}

In this study, Slovenia was chosen as a case study for planning scenarios related to the dynamics of the transition of agricultural holdings with the potential for tourism activities to tourism farms. Slovenia is characterized by a varied geographic configuration, a diverse cultural heritage and rich and sundry natural resources. The natural conditions have influenced the dispersed settlement of the population. As much as $86.9 \%$ of Slovenia is classified as a less-favoured area (LFA) for agricultural activity, which represents $76.2 \%$ of the total utilised agricultural area (UAA). Due to several characteristics affecting agricultural structures (e.g. the location, effects of climate changes, and harsh economic and social conditions), most Slovenian farms cannot survive on income from agricultural activity alone. Thus, the diversification of non-agricultural activities in farms is an important aspect of scientific and expert discussions. 
According to Hill (2018), the effects of agricultural and non-agricultural activities diversification have been little studied. Agricultural diversification can help farms survive and stimulate competitiveness and innovativeness in all types of farms in all regions of Slovenia. These activities be pursued as priority assignments within the European Union (EU). At the same time, however, we must ensure that the goals of the EU align with the goals of diversification, as diversification is a critical factor in supporting the development of the countryside. Agricultural policy decisions can have long-term consequences.

Slovenia has been facing a decline in farming in recent years (see Figure 1; SORS, 2020a). One factor influencing this trend is farm income, which can be improved by the diversification of primary activities. In 2020, due to a reduction in the number of agricultural holdings, concerns arose about ensuring the self-sufficiency of Slovenian food production (Rossi, 2020; IPES-Food, 2020; Rubiah and Elamin, 2021; Pulighe and Lupia, 2020).

By preserving agricultural holdings, the cultural landscape is preserved, agricultural land is cultivated and fewer fields are left fallow. We want agricultural establishments to remain as active as possible. Therefore, policy planning is required to prevent holding abandonment. At the same time, we want farms to diversify their activities so that they can increase their income. It is important to note that the number of tourist arrivals and overnight stays in Slovenia has increased significantly in recent years (see Figure 2; SORS, 2020b).

The question is how agricultural holdings can exploit the potential opportunities provided by a thriving tourism industry while reducing the number of agricultural holding closures. To address this question, this study uses a systems approach that considers all factors and feedback loops. The results of this study can help policymakers plan for the further development of the industry.

\subsection{Causal loop diagram (CLD)}

Based on the above description of the situation and the definition of the issues, the following CLD was created (Figure 3). Different feedback loops that indicate amplification (R1, R2) and equilibrium (B1, B2, B3, B4) were identified. Reinforcing $(R)$ means that the effect increases over the value it would normally have if the cause increases. In contrast, Balancing $(B)$ means

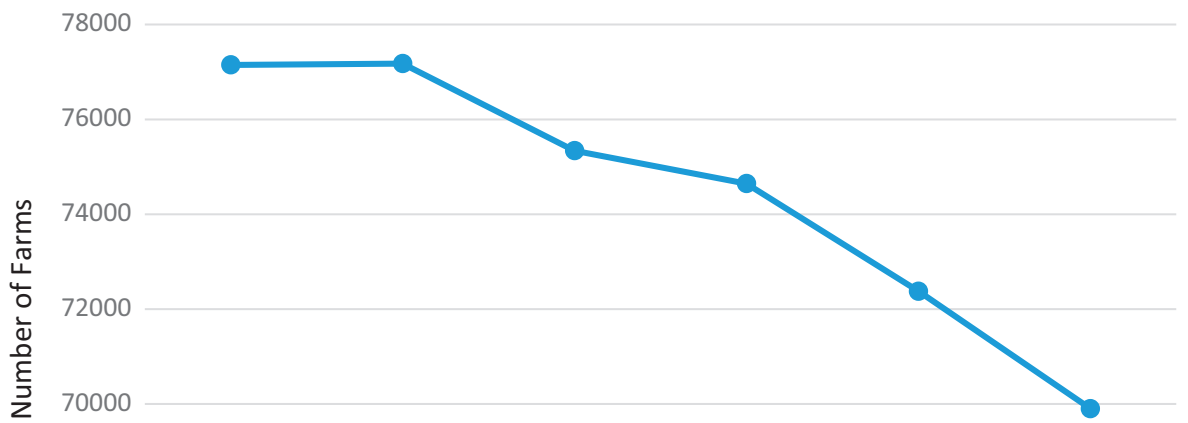

68000

66000 2003

2005

2007
Year

2010

2013

2016

Source(s): SORS (2020a)
Developing a diversification strategy 
$\mathrm{K}$

51,13

38

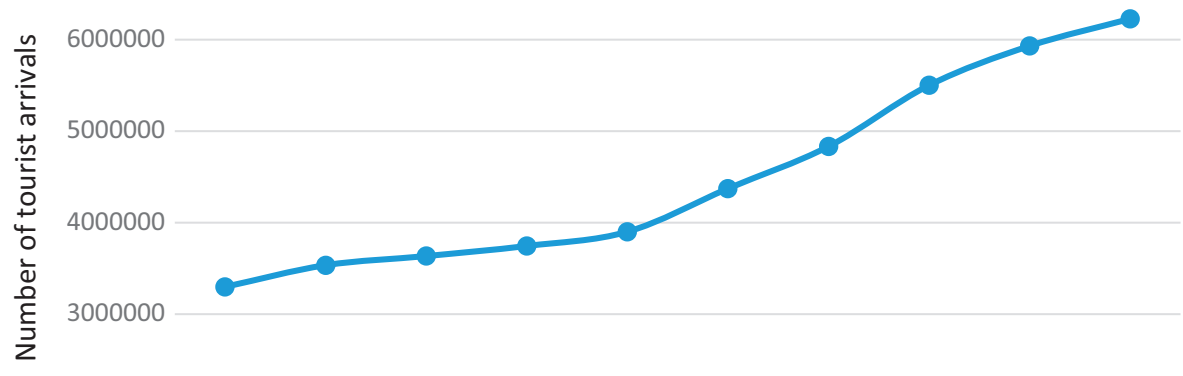

2000000

1000000

0

$\begin{array}{llllllllll}2010 & 2011 & 2012 & 2013 & 2014 & 2015 & 2016 & 2017 & 2018 & 2019\end{array}$

Number of tourist arrivals in Slovenia from 2010 to 2019

Source(s): SORS (2020b)

that the consequence is reduced below the value it would normally have if the cause increases. When the system elements are interconnected and form a closed sequence of causes and consequences, the result is a causal loop.

Loop B1 represents a balancing loop. Farms strive to generate as much income from their activities as possible. They would also be able to do this through diversification. In Slovenia, the number of agricultural holdings that diversified their primary activity declined slightly in the last period (between 2015 and 2018). However, the number of subsidiary activities in tourism grew (Chamber of Agriculture and Forestry of Slovenia [CAFS], 2019). The decline in diversification can be linked to the requirements of the Decree on Subsidiary Activities on Farms (Official Gazette of the Republic of Slovenia, number 57/15 and 36/18), which strengthened the relationship between farms and basic agricultural activities. In contrast, between 2004 and 2014, the number of subsidiary activities in Slovenia increased by 507\% (SORS, 2020c). With the B4 feedback loop, we identified a gap that restrains growth in the number of diverse farms. Specifically, income per farm decreases as the number of tourist farms increases. This inhibits the transition of diversification.

On the global level, the tourism sector in 2019 contributed to $10.3 \%$ of global GDP and $9.9 \%$ of national GDP in Slovenia (WTTC, 2019). This is also affected by tourist farms. With the return contribution of income per farm, agricultural holdings can prompt new investments in tourism due to the increased attractiveness of diversification related to increased income (R2).

As the number of tourist farms increases, information about the positive effects of activities on farms spreads (R1) by word-of-mouth. This may prompt additional farms to diversify their activities. Farms can use this promotion tool as tool to market the accommodation capacities and activities they offer (Król, 2019).

In negative feedback loop B2, the number of tourists increases the number of tourists per diverse farm, which might cause crowding. This has a negative impact on new arrivals, leading to a decrease in the number of tourists. Loop B3 represents the delay structure, which is dependent on the average length of stay. 


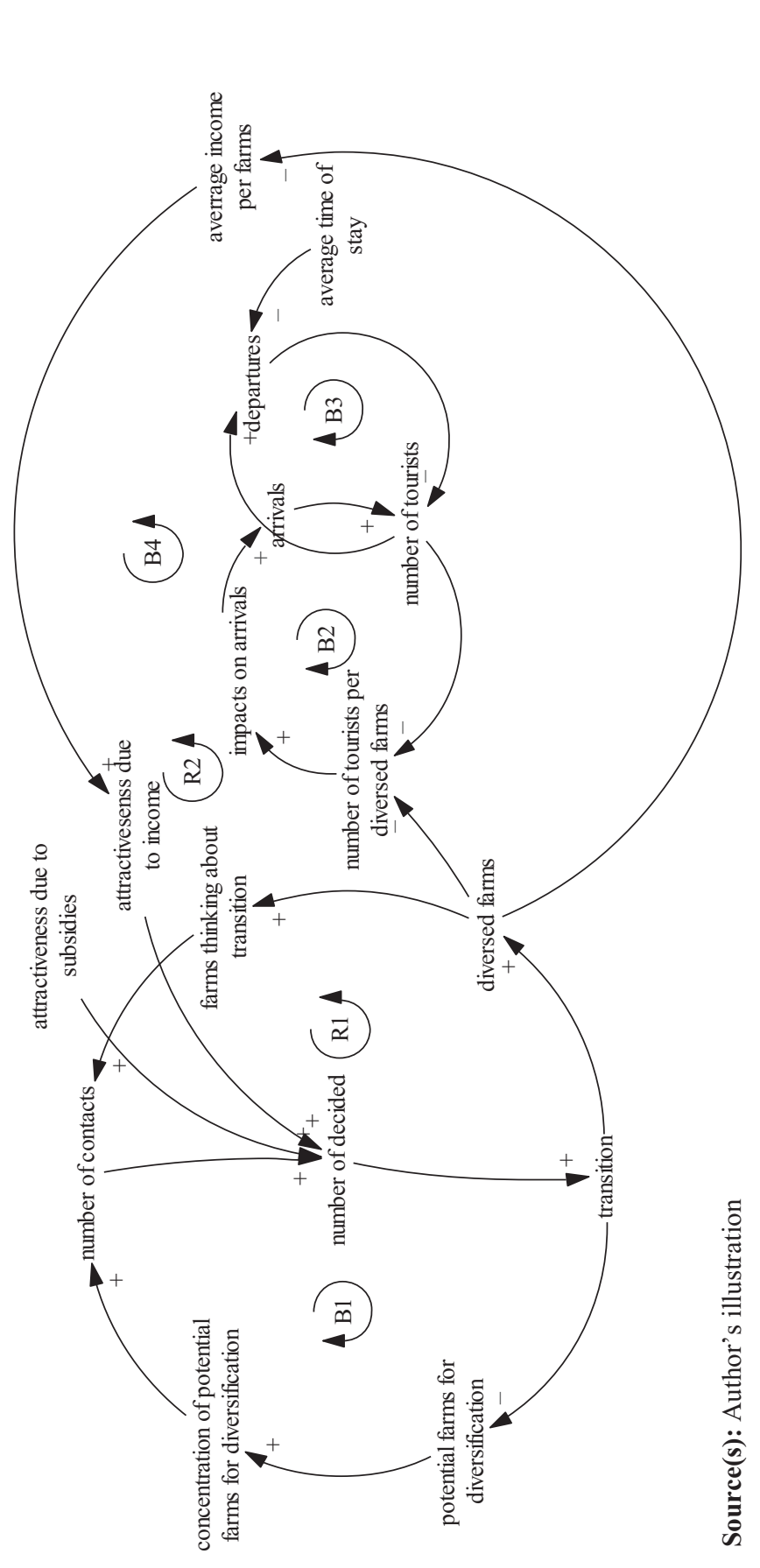

Developing a diversification strategy 
$\mathrm{K}$

51,13

40

\subsection{Developing the model}

Based on the CLD, we prepared an SD model structure defined by mathematical equations. The model was developed using AnyLogic 8.2.3 Personal Learning Edition software. The structure of the SD model is shown in Figure 5. Such models are used to illustrate the behaviour of a real system while testing the effects of alternative decisions over time.

The model structure shows several state variables, including diversified farms, potential farms for diversification (i.e. farms that are suitable for transition, having an acreage of 10-15 ha of the UAA; CAFS, 2019), and the number of tourists on tourist farms. Other variables that affected or evaluated the state variables were added to the model (e.g. the total number of farms, number of contacts, subsidies, average stay time, average income). Each stock condition, variable and relationship in the model includes a mathematical equation that shows a sort of reciprocal relationship.

The flow "transition" refers to the transition from a conventional farm to a diversified one. According to the AJPES-Slovenian Business Register (2020), there are 773 tourist farms in Slovenia (Figure 4). In the model, we also considered the decreasing number of farms in Slovenia. On average, $1 \%$ of farms were lost each year in the last period (2003-2016) (SORS, 2020a). "PotentialFarmsForDiversification" was influenced by the element "closing Farms", which was calculated by multiplying "ratioOfClosing" with the function "impact Of Diversification On Closing" and "potential Farms For Diversification". Tourism as an industry and the number of tourists in a given area play an important role in the transition of an agricultural holding to a tourist farm. The yearly growth of tourism is input into the graph function. When the yearly growth of the tourism branch is $8 \%$, the growth in new diversified farms is approximately $1 \%$. This can also be used, with some correction, to determine how many of the farms that consider transitioning will actually do so.

The equations incorporate real data and information from Slovenia regarding the problem. Thus, our model seeks answers to strategic questions related to the dynamics of the transition of agricultural holdings to tourist farms to achieve higher revenue in addition to primary activities. The model was simulated through several scenarios. Appendix presents a summary of the mathematical equations used.

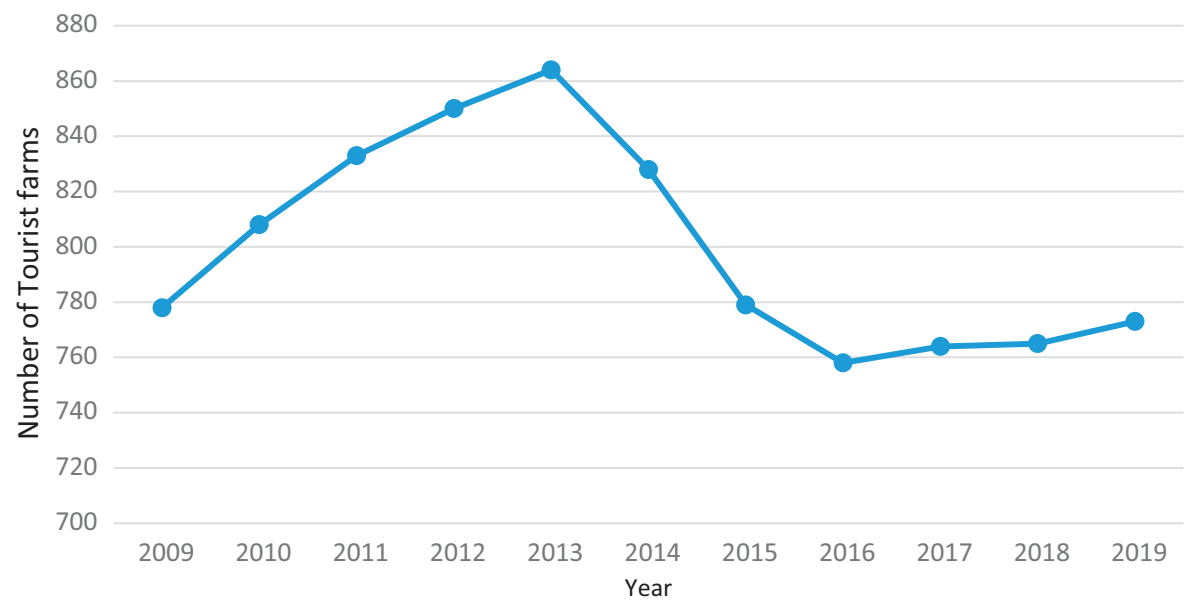

Source(s): AJPES -Slovenian Business Register (2020)
Figure 4.

Number of Tourist farms in Slovenia from 2009 to 2019 


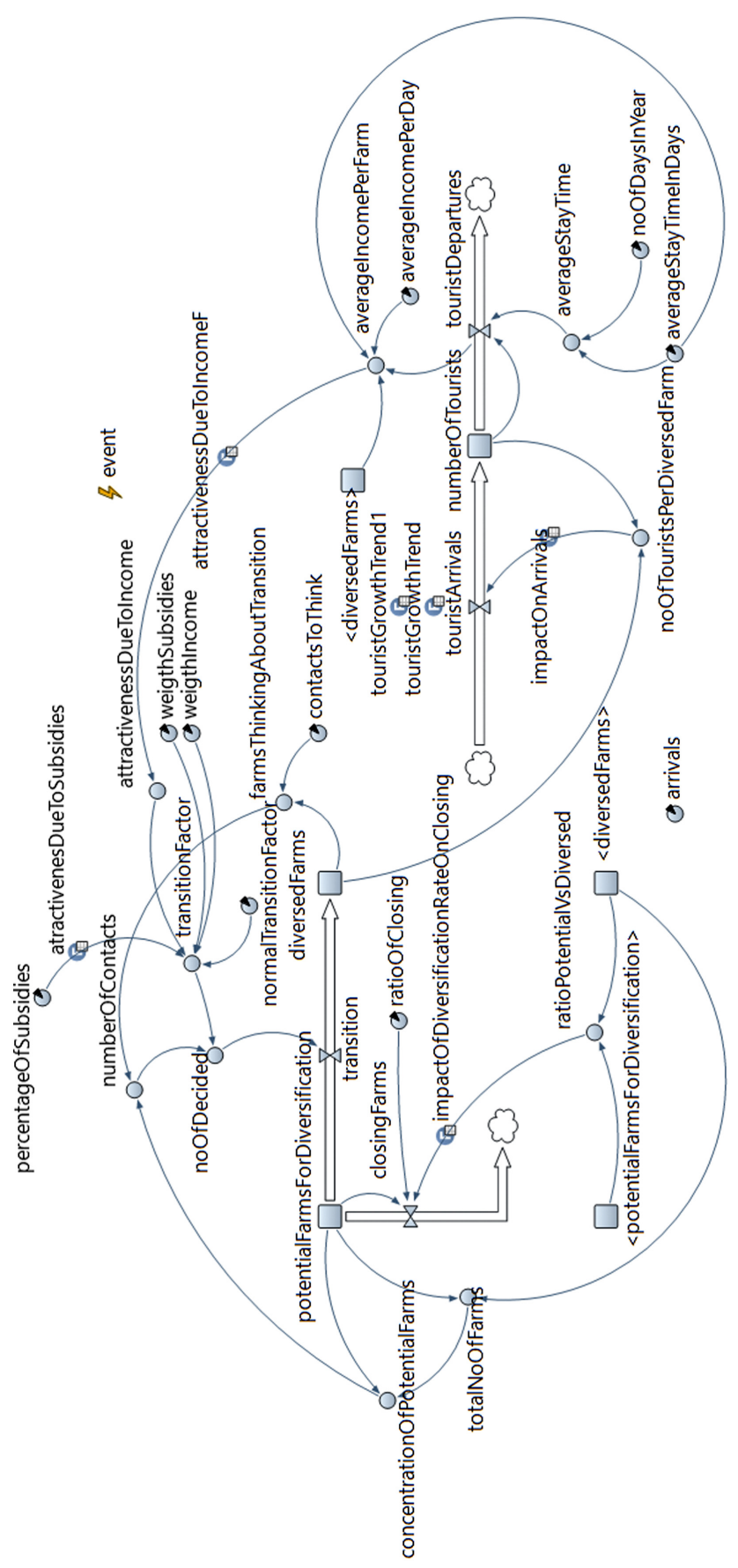

Developing a diversification strategy

41

Figure 5.

System dynamics model 
$\mathrm{K}$

51,13

42

\subsection{Validation}

Validation is an important modelling process in which the model is tested under known conditions, and the results are checked against real system data. Summary statistics of historical fit (Sterman, 1984) are a standard validity test for SD models (Oliva, 1995). Rahmandat and Sterman (2012) emphasize the importance of validation. With validation, we also checked whether the built-in functions gave a variable output when the model parameters changed. We wanted to verify that none of the functions was stuck at a constant value or, for example, at the minimum or maximum output value. The validation was performed on $n=11$ points according to the following equations for Theil statistics (Oliva, 1995). The coefficient of determination is defined as follows:

$$
r^{2}=\left(\left(\frac{1}{n} \sum_{t=1}^{n}\left(S_{t} A_{t}\right)-\overline{S A}\right) / S_{S} A_{A}\right)^{2}
$$

Mean absolute percent error (MAPE):

$$
\mathrm{MAPE}=\frac{1}{n} \sum_{t=1}^{n}\left|\frac{S_{t}-A_{t}}{A_{t}}\right|
$$

Bias component of MSE (mean squared error):

$$
U^{m}=(\bar{S}-\bar{A})^{2} / \mathrm{MSE}
$$

Variation component of MSE:

$$
U^{s}=\left(S_{S}-A_{A}\right)^{2} / \mathrm{MSE}
$$

Covariation component of MSE:

$$
U^{c}=2(1-r) S_{S} A_{A} / \mathrm{MSE}
$$

where $A_{t}$ are actual numbers of diversified farms yearly and $S_{t}$ are simulated values provided by the model.

Table 1 shows the results of the Theil validation statistics for the number of diversified farms. The real data and simulation data are compared in Figure 6. Data in the field of farm diversification are scarce, so only quantitative validation of the number of diversified farms was possible.

We also performed a structure verification test (Senge and Forrester, 1980). Here, we considered two discrete variables: subsidies and the closing of farms. The structure's

\begin{tabular}{lc}
\hline Validation statistics & Value \\
\hline Number of data points $(n)$ & 11 \\
Coefficient of Determination (R2) & 0.960827 \\
Mean Absolute Percent Error (MAPE) & 0.010206 \\
Mean Square Error (MSE) & 171.7407 \\
Root Mean Square Error (RMSE) & 13.10499 \\
Bias component of MSE (Um) & 0.135469 \\
Variation component of MSE (Us) & 0.485172 \\
Covariation component of MSE (Uc) & 0.379359 \\
Correlation & 0.98
\end{tabular}

Table 1.

Validation statistics

$$
\text { Correlation }
$$




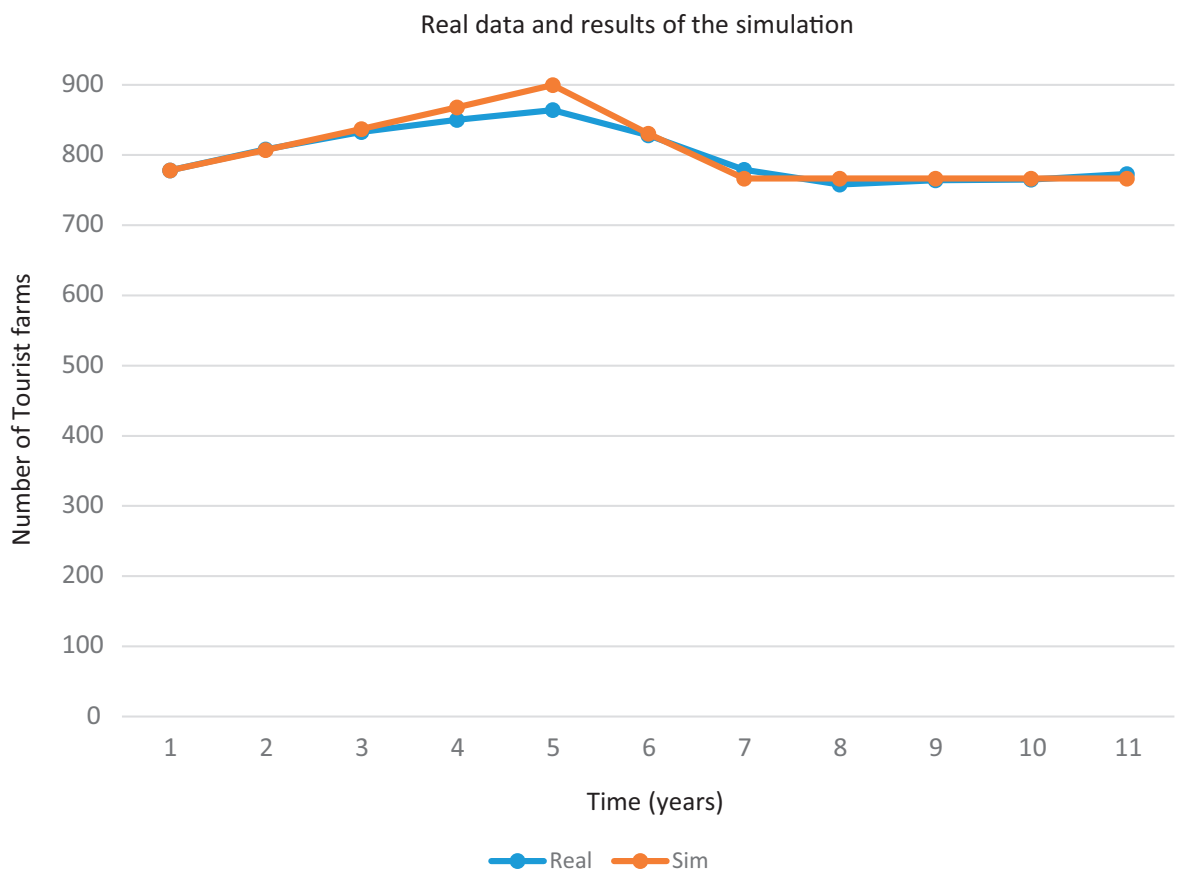

Developing a diversification strategy

response to unpredictable situations also proved that the structure was appropriate. We also considered the COVID-19 situation, which effectively stopped tourism for a time. In this case, the model also provided viable results, which confirmed the appropriateness of the structure.

The R2 value of 0.96 shows an acceptable correlation. The MAPE result also represents a very low deviation from the real data: $<1 \%$ for the observed simulation run. The bias component of the MSE Um is $<14 \%$. However, unequal variation Us accounts for $49 \%$ and the covariation component of MSE Uc for $38 \%$, indicating that simulated dynamics track the real process; however, it diverges point-by-point because of the random component of the diversified farms' dynamics.

For more accurate validation, more data related to diversification itself should be collected. The problem is that there are no unifying institutions that monitor diversification statistics, and the data itself is difficult to obtain. Nevertheless, the computed Theil statistics provide encouraging results for future model development.

\subsection{Scenario generation}

After validation, different scenarios were generated. Scenario analysis is a qualitative tool for strategic policy analysis that enables researchers and policymakers to support decisionmaking and systemic analysis of the main determinants of a business or sector (Zanoli et al., 2012). To create reality-based scenarios, data on the real system must be collected. First, we identified the leverage indicators that defined our model. For that, we set out "diversified farms", "closing farms" and "transition". Several scenarios can be analysed according to the following parameters: "ratioOfClosing", "contactToThink", "averageStayTimeInDays", "averageIncomePerDay" and "percentageOfSubsidies". Table 2 shows the values of these parameters for all 11 scenarios. The italic fields represent the differences in the parameter values compared to the previous scenario. 
$\mathrm{K}$

51,13

44

Scenarios 1 and 2 - Significant increase and reduction of subsidies representing refundable or non-refundable funds to farms as an aid to start or develop activities further. The argument of $50 \%$ and $100 \%$ subsidized activities were defined in the graph of the function as values 1 and 2, respectively. According to data from the Agency for Agricultural Markets and Rural Development, with regard to the Rural Development Program from 2014 to April 2020, no funds were allocated for investment support activities in the establishment and development of non-agricultural activities (Agency for Agricultural Markets and Rural Development [AAMRD], 2020). Between 2007 and 2013, quite a few funds were distributed for nonagricultural activities, including the development of tourist farms (AAMRD, 2020). Their allocation is shown in Figure 7.

In 2008, the global financial crisis began. Until 2014, funding continued to increase the number of tourist farms. After 2013, growth declined. It bounced back in 2016 thanks to the favourable development of the tourism industry and a large number of tourist arrivals and overnight stays in Slovenia.

Scenarios 3 and 4 - Significant increase in profit or possible situation when a farm does not receive income from tourism (COVID-19 and travel ban). The annual tourist income per tourist farm amounts to $€ 46.65$ days, while the average length of stay of a tourist on a tourist

Table 2.

Diversification to a non-agricultural activity on the farm scenarios evaluated for Slovenia

\begin{tabular}{lccccc} 
Scenario & ratioOfClosing & contact ToThink & averageStayTimeInDays & averageIncomePerDay & percentageOfSubsidies \\
\hline 1 & 0.01 & 2 & 2.31 & 20.19 & 25 \\
2 & 0.01 & 2 & 2.31 & 20.19 & 0 \\
3 & 0.01 & 2 & 2.31 & 200 & 55 \\
4 & 0.01 & 2 & 2.31 & 20.19 & 50 \\
5 & 0.01 & 2 & 1 & 20.19 & 50 \\
6 & 0.01 & 0.5 & 6 & 20.19 & 50 \\
7 & 0.01 & 10 & 2.31 & 20.19 & 50 \\
8 & 0.01 & 2 & 2.31 & 20.19 & 50 \\
9 & 0.005 & 2 & 2.31 & 20.19 & 50 \\
10 & 0.02 & 2 & 2.31 & 0 & 50 \\
11 & 0.01 & 0 & & & 0
\end{tabular}

Figure 7.

Granting of subsidies between 2007 and 2013
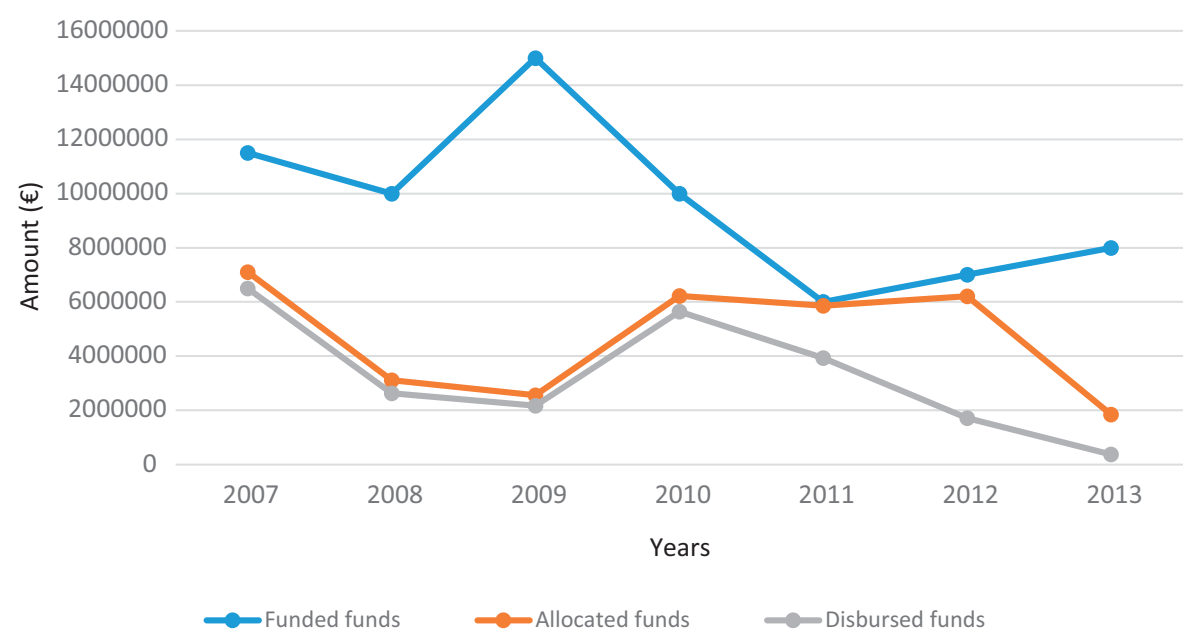

Source(s): AAMRD (2020) 
farm in 2019 was 2.31 days. Therefore, the average income is estimated to be $€ 20.19$ (MKGP, 2019).

Scenarios 5 and 6 - Significant increase or decrease in residence time on a tourist farm. Together, this factor and the previous one describe the income that tourist activity brings to an agricultural holding. The length of stay of tourists on a tourist farm significantly influences the transition of agricultural holdings to tourist farms.

Scenarios 7 and 8 - Decrease and increase in the "contact to think" constant. Hines (2017) describes a similar principle in the model called diffusion. One newly diversified farm will prompt two other farms to consider transitioning. Yearly, $1 \%$ out of 5415 potential farms for diversification becomes diversified (i.e. 54 farms a year).

Scenarios 9 and 10 - Decrease and increase on the parameter "ratio of closing". On average, $1 \%$ of farms in Slovenia closed every year between 2003 and 2016. That presents an element, "ratioOfClosing". In the model, we set this as a constant of 0.01 .

Scenario 11 - Closed subsidies, no income from tourists, and no overnight stays. This scenario considers what happens to the transition of potential farms to tourist farms when the tourism industry stops (the case of spring 2020 and the COVID-19 pandemic), and the state does provide support to agricultural holdings by means of subsidies.

Based on the 11 scenarios described above, we obtained important results (see Figures 8-10). The time units of our simulations are presented in years, representing the period between 2020 and 2070. We can expect that the parameters we set in this model will not be constant during the longer time horizon. However, such a simulation assists in the analysis of the influence of key parameters on the model's response.

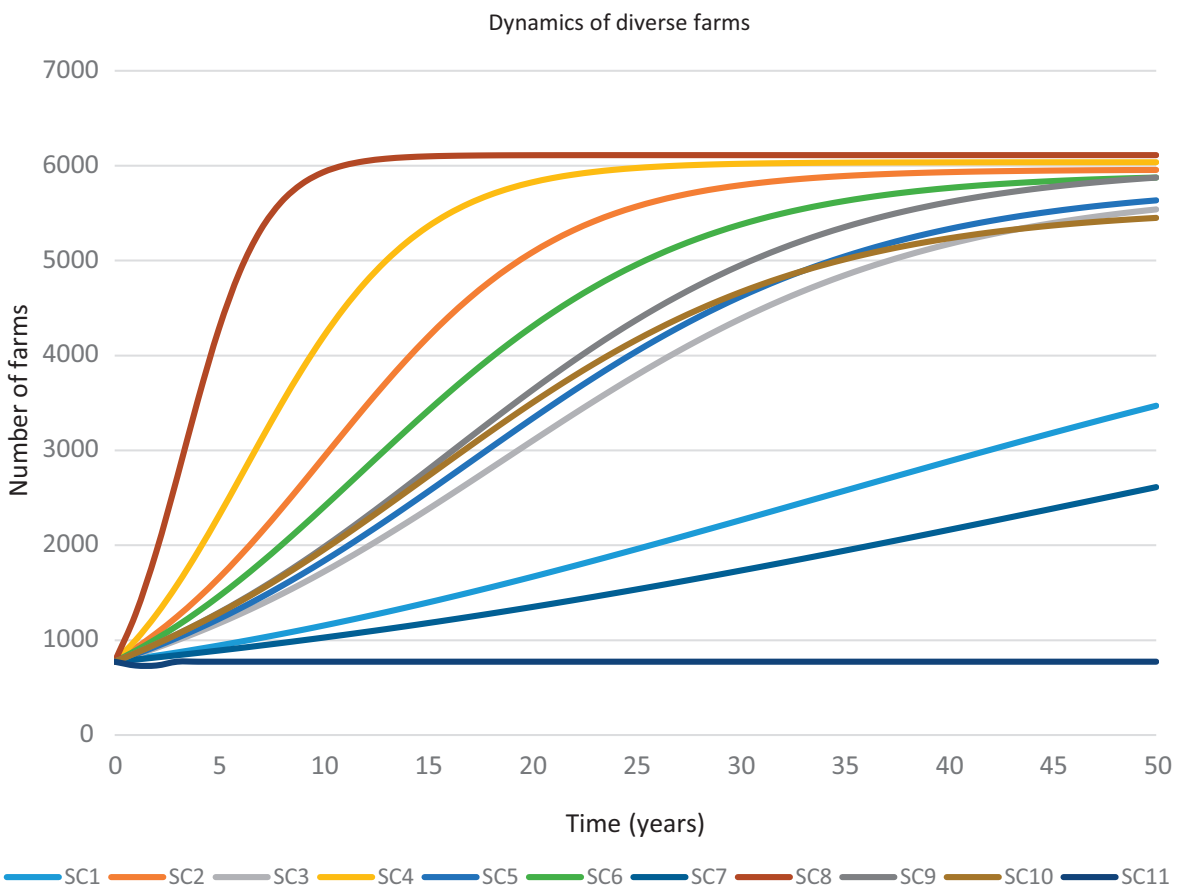

Developing a diversification strategy 
$\mathrm{K}$

51,13

46

Figure 9.

Example of eleven performed scenarios showing the dynamics of closing farms

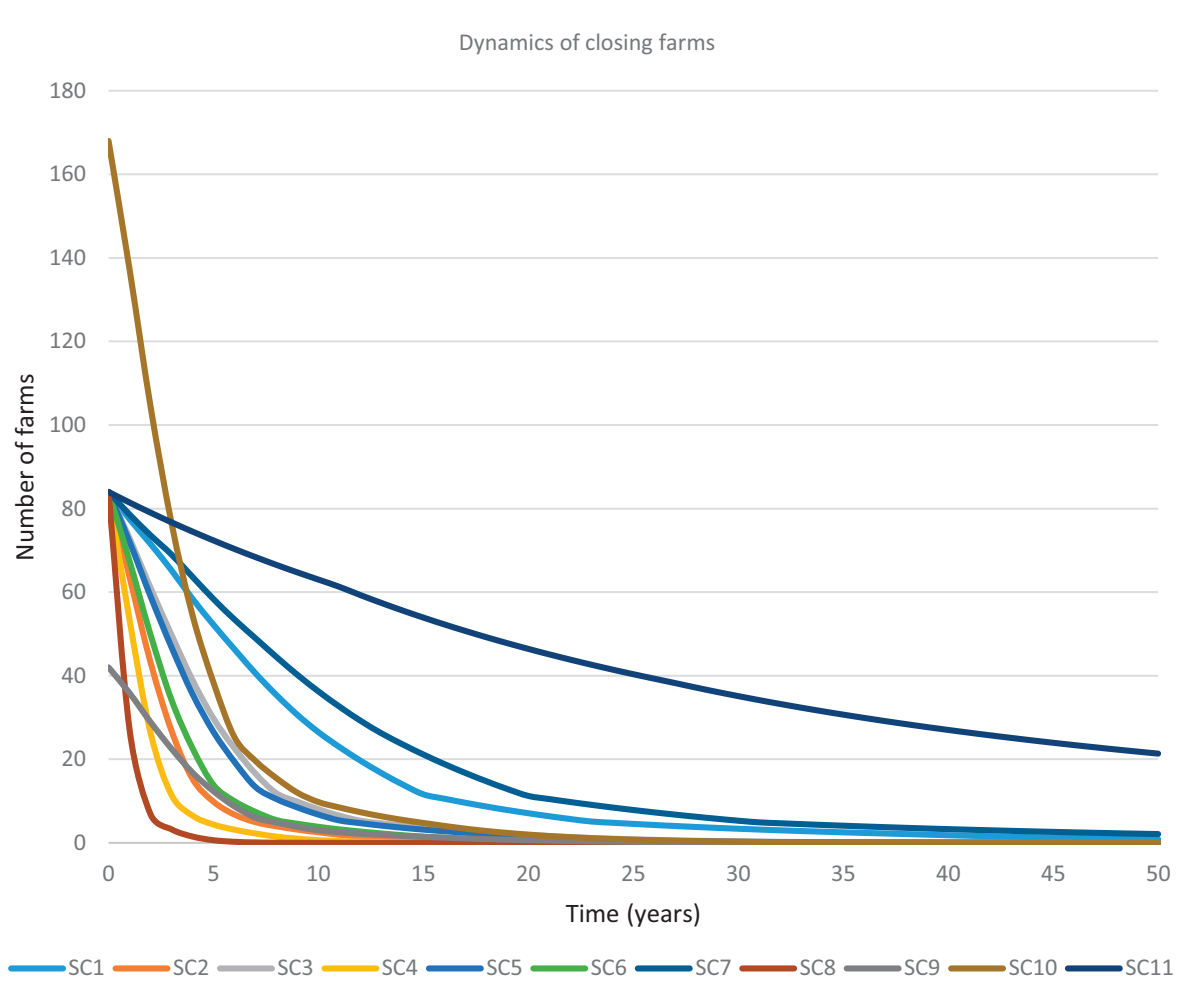

\section{Discussion}

4.1 Changing the "contact to think" parameter

An important finding derived from the results is that the system is highly responsive to the "contact to think" variable, which is indirectly associated with the importance of promotion. This is shown in all three graphs by simulations of SC 7 and 8. In Figure 8, SC 7 shows the number of diversified farms. The number grows slowly. In the next time horizon of 50 years, there will not be a distinct increase in the number of tourist farms. We see the same in the transition graph (Figure 9). There is almost no diversification of the activity from potential tourist farms. This activity is associated with the "contact to think" factor.

The promotion is key to success in tourism development, combined with infrastructure, hospitality, attractiveness and appropriate service activities (Gunn, 1988). In contrast, a high share of "contact to think" represents a diametrically different picture (SC 8). After 10 years, given the conditions, potential farms would take advantage of opportunities for diversification. The share of farm closures would decrease significantly, and the transition would peak after 5 years.

\subsection{Changing the "percentage of subsidies" parameter}

A similar effect on the promotion system is also perceived in terms of the use and consumption of subsidies. The higher the subsidies (see SC 2), the faster and more distinct the transition of potential farms to tourist farms (Figure 10). The opposite is also true (SC 1): when subsidies are very low, the rate of transition is slow and low. However, transitions occur, which suggests that the system is not entirely dependent on subsidies alone. This can also be 


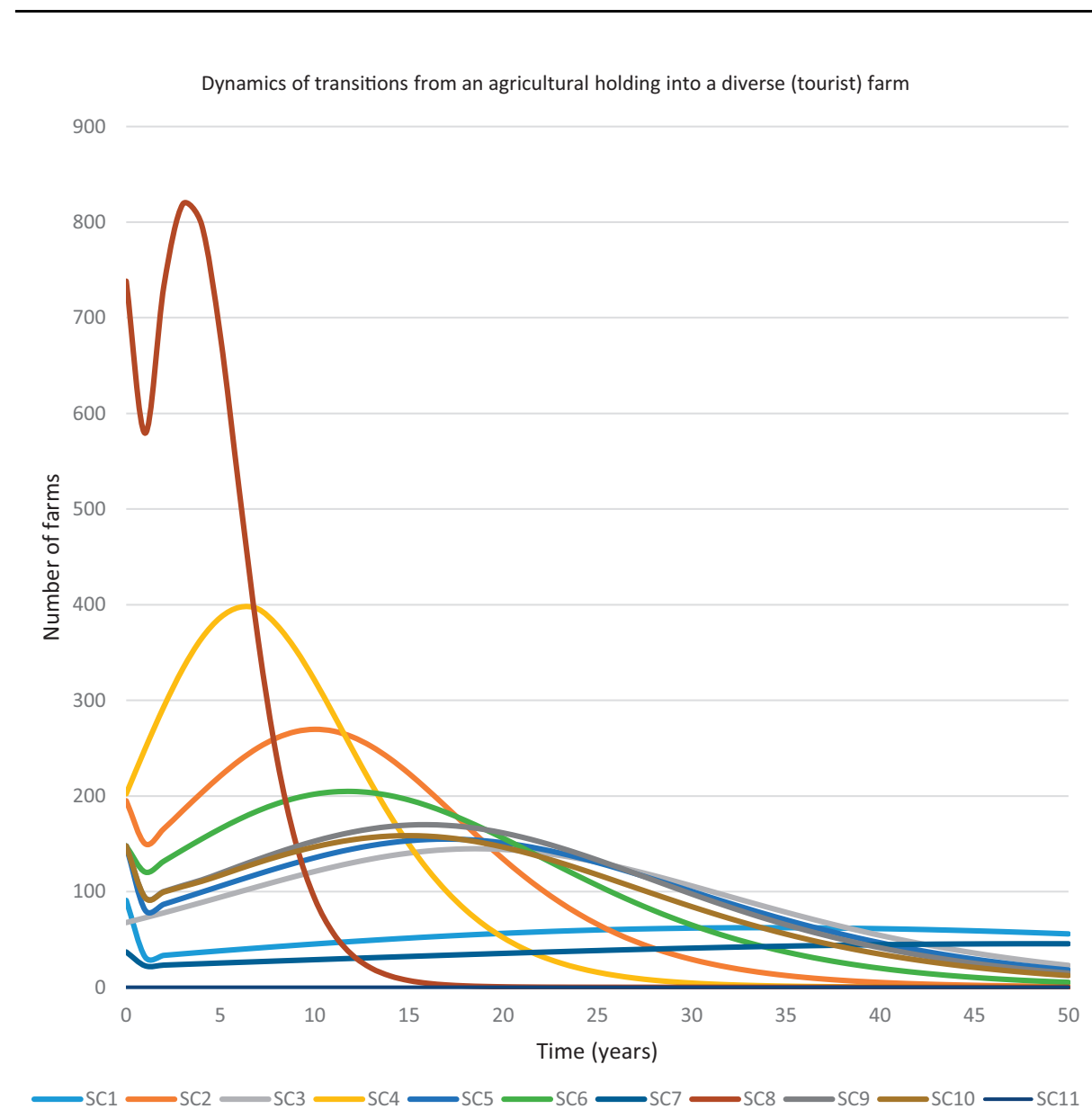

Developing a diversification strategy

proved with SC 3 when we take away the tourism profits of the farms. The consequence of this is that not all potential farms achieve diversification in this area. However, transitions still occur because they are encouraged by subsidy mechanisms. The state assists farms with minimal income through various mechanisms.

In the spring of 2020, the COVID-19 pandemic emerged, which had a strong impact on tourism. In SC 11, we examined what happens if farms do not feel the effects of tourism (e.g. if the tourism industry stops) and, at the same time, the state does not help with subsidies. The results of the scenario show that no new farms transitioned to tourist farms. However, a large percentage of the gradual closure of farms remains. Such a result is logical because it would not make sense for farms to diversify activities that are not profitable. The question is whether the state could help with long-term subsidies if the income was zero in the long run. These are important issues that open up areas of self-sustaining resources for tourist farms.

\subsection{Changing the "average income per day" parameter}

As farms diversify their primary activity with tourism, this opens up other opportunities for the development of additional subsidiary industries, such as the sale of domestic products, 
$\mathrm{K}$

51,13

48

bread and pastry baking, juice production and the development of theme parks. All of these industries bring in additional earnings. To answer the previous question, therefore, we refer to SC 4, in which we significantly increased the income left by tourists on a tourist farm. SC 4 shows the best results concerning the system response. The number of diversified farms increases (Figure 8), the rate of farm closures rapidly decreases (Figure 9), and the rate of transition grows significantly in the first 8 years (Figure 10), after which it slowly declines before stabilizing after about 30 years. A fairly high transition rate is also attributed to SC 2 (Figure 10), described previously. This reaffirms the importance of the strategic issue of subsidizing activities.

\subsection{Changing the "average stay time in days" parameter}

As mentioned earlier, the average length of stay influences the rate of transition of potential farms to tourist farms. In SC 6, we increased the length of stay of tourists on a tourist farm, resulting in a higher income from tourists to the farm. SC 5, 6, 9 and 10 show similar results, though the differences between SC 5 and 6 are more obvious than the differences between 9 and 10 , which indicates the importance of the "average stay time in days" parameter. In SC 6, we wanted to examine what happens if tourists' length of stay on tourist farms increases. The number of farms that have diversified their activities is quite high. The curve is distinctly S-shaped. After about 35 years, the number of diversified farms stabilizes. The transition is similar: up until about the 15th year, the rate of transition grows. After that, it begins to fall. It stabilizes after approximately 35 years, when the number of potential farms for transition also peaks with diversification. In contrast, the curve in all three graphs shows that SC 5 approaches the curves of SC 1 and 3 when very low operating income and low subsidies are entered into the system. Therefore, the "average stay time in days" parameter for such a system is essential.

\subsection{Changing the "ratio of closing" parameter}

SC 9 and 10 represent a change in the "ratioOfClosing" variable. Both scenarios show moderate transition growth. SC 9 is slightly higher, which is clear because the constant of farm closure is lower than the constant shown in SC 10. Based on the observed elements, we can conclude that this variable has the smallest impact on the diversification of nonagricultural activities on agricultural holdings, which are connected to the field of tourism.

\subsection{Impact of the "attractiveness to diversify due to income" variable}

In addition to the simulations of the above scenarios, we produced a graph of the results that significantly contribute to diversification decisions. This figure defines "attractiveness to diversify due to income" (Figure 11). Here, we assume that farmers are attracted by the potential income increase associated with investing in diversification. In the CLD diagram, the B4 feedback loop revealed that as the number of tourist farms increases, the income per farm decreases as tourists are spread among more providers. Therefore, the sum income from tourism activities is dispersed to more and more tourism capacity providers. Figure 11 also illustrates the parallel. The effect of the additional increase in income (SC4) on agricultural holdings is seen after a significant delay. Initially, the newly established capacity of farms is so large that the trend of expected income per farm decreases. It begins to rise after a significant delay of approximately 10-15 years. One should, therefore, consider the countereffect when increasing capacity since the average income per farm will decrease at first.

\subsection{Practical (managerial) implications of the model}

The main managerial insight of the model is its ability to provide additional information and directives to agricultural policymakers. Its main advantage is the possibility of 


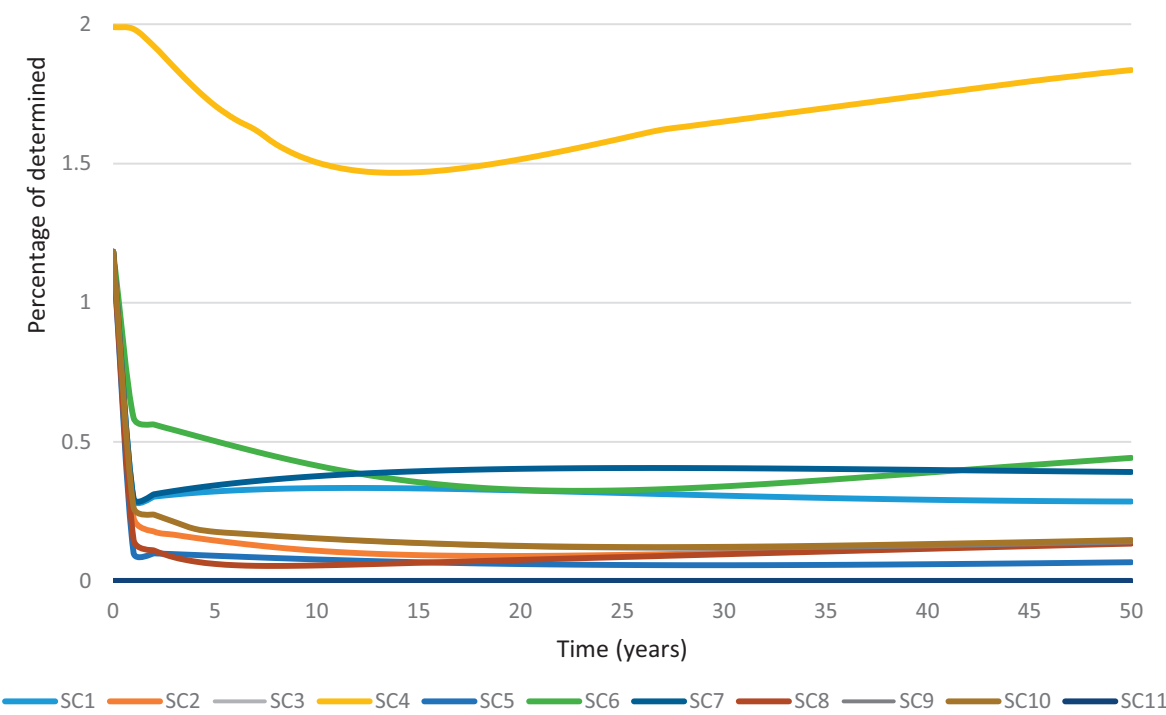

experimenting with model scenarios when limited data are available, which gives policymakers information regarding the system's potential response to different policies prior to making any decisions. It is genuinely important for managers in strategic positions (including politics) to develop a model that represents resource management in a dynamic and complex modern environment. The developed model has shown that subsidies play an important role in the diversification of non-agricultural activities on farms, which has not been completely considered in past policymaking. The model warns managers and policymakers not to base their decisions on past decisions.

The model does not offer exact numerical predictions, but it does show the main trends and impacts of parameter variations. The model and scenarios represent policies that examine key variables and their behaviour over time, depending on the key parameters. Through validation and simulations, we improved our understanding of the impact of individual variables. At the same time, the model also allowed us to explain the simulation model response in certain scenarios. Because simulation allows us to adjust variables over time, it is possible to test many scenarios in advance. These are concrete tools that can help in the actual planning of real-world agricultural policies. The presented methodological framework can provide additional clarity to agricultural policy decisions and thereby play a significant role in the further development of farm tourism.

\section{Conclusion}

In this paper, we analysed the importance of the diversification of non-agricultural activities on farms in Slovenia, that is, the dynamics of the transition of potential agricultural holdings to tourist farms. Slovenia lies at the heart of Europe. It is a transit country with favourable 
$\mathrm{K}$

51,13

50

climatic living conditions, located at the crossroads of the Alpine, Pannonian, Dinaric Karst and coastal landscape. These characteristics draw many tourists to the country annually. However, the number of agricultural holdings in Slovenia has been declining significantly, partly because basic agricultural activity produces insufficient income for farming to be considered a profitable activity.

The income position of agricultural holdings can be improved with the introduction of subsidiary activities on farms. One such activity is farm tourism. Our SD model enables simulations of different scenarios and policies. These make explanations in decision-making processes possible for a wider population of decision-makers. By defining leverage indicators in the system (i.e. "diverse farms", "closing farms" and "transition"), we were able to formulate a mathematical model.

Eleven different scenarios were tested at these leverage points. We came to some important conclusions based on the simulations. The system of diversification of agricultural holdings into non-agricultural activities connected with tourism primarily responds to five different factors: "ratioOfClosing", "contactToThink", "averageStayTimeInDays", "averageIncomePerDay" and "percentageOfSubsidies".

The "contactToThink" factor, which is associated with promotional activities in the real world, was one of the most important parameters. Two types of promotion were considered: the positive effects that subsidiary activity brings to the agricultural economy (tourism is represented as a catalyst for the economic challenges of rural areas; Williams and Shaw, 1998) and the promotion of tourist farms. These promotions are the tools available to farms or broader groups of entities that allow them to communicate with their target public (Podnart and Golob, 2001).

Another important parameter that affected our system was subsidies. Simulations and model development led us to question the extent to which it makes sense to encourage such activities and when development should be replaced by self-supporting resources. Given our model and the current number of tourist farms in Slovenia, this should not be an overly difficult problem for decision-makers in agricultural policies because the number of tourist farms is quite low. At the same time, the amount of subsidization of start-up and development activities is low and resources unused. Therefore, the government still has significant room to manoeuvre in this area.

The model was significantly influenced by two other factors: the length of the stay of tourists in Slovenia and the income produced by tourists to a farm. These two variables, together with high growth and further development of activities, influence the negative impact that tourism can have on the environment (negative consequences of overtourism) and on agricultural holdings because a significant increase in the number of tourist farms would reduce the income per tourist farm. Nevertheless, further development of the activity should consider the interaction between all five parameters and the feedback loops that influence the system's operations.

In the present study, a novel concept was observed and discussed. Through SD and policymaking, this produced a new tool that enables a detailed analysis of various scenarios that affect the cessation of farm abandonment.

The research was limited by the small set of available data due to the limited number of farms in Slovenia. One of the major problems is the different statistical data collected for the same activities by individual empowered institutions in Slovenia, which, unfortunately, are not connected: on the one side, the Ministry of Agriculture, Forestry and Food, and on the other side, the AJPES-Slovenian Business Register and the SORS. All three recorded different numbers of tourist farms in Slovenia. The constraint is represented by variables for which it is difficult to determine empirical data. Unfortunately, subjectivity cannot be avoided in such cases. This involves the functions that represent the effects of subsidies on the transition of farms, the influence of diversification on the rate of abandonment of agricultural 
activity and other functions used in the model. The values of these functions in the model are based on certain expert foundations. All values were tested but were not derived empirically.

To gain even more insight into the situation, models should be developed based on alternative methods (e.g., econometric models or agent-based models) in cases where sufficient data are available. At the same time, a multicriteria analysis of scenarios is possible. Research can also be improved by the visual interactive modelling method.

The research and simulation of the scenarios were prepared for the field defined by the state of Slovenia. A similar approach is also possible for other countries or regions facing similar issues; that is, areas that are looking to increase income in basic agricultural sectors, especially in areas suitable for diversification into non-agricultural activities. Since Slovenia is a relatively small country, it would be interesting to test scenarios that cover larger areas. Models would likely behave differently under different circumstances. The advantage of SD is the ability to experiment with different scenarios and produce results that show potential solutions even before certain decisions are made.

\section{References}

Adesina, A.A., Mbila, D., Nkamleu, G.B. and Endamana, D. (2000), "Econometric analysis of the determinants of adoption of alley farming by farmers in the forest zone of Southwest Cameroon”, Agriculture, Ecosystems and Environment, Vol. 80 No. 3, pp. 255-265, doi: 10.1016/ S0167-8809(00)00152-3.

Agency for Agricultural Markets and Rural Development (2020), Analysis of Application Processing and Absorption of Funds within the PRP 2007-2013, Internal material, AAMRD-Agency for Agricultural Markets and Rural Development, Lljubljana.

Ahmadvand, A., Bastan, M. and Nasiri, M. (2013), "Strategic map explanation dynamics analysis using a system dynamics approach", 9th International Conference on Industrial Engineering, Khajeh Nasir Toosi University of Technology, Tehran.

AJPES-Slovenian Business Register (2020), Number of Business Entities with Main Activity 55. 202 or 56.105 by Years, Internal material, AJPES-Slovenian Business Register, Ljubljana.

Arroyo, C.G., Barbieri, C. and Rich, S.R. (2013), "Defining agritourism: a comparative study of stakeholders' perceptions in Missouri and North Carolina”, Tourism Management, Vol. 37, pp. 39-47, doi: 10.1016/j.tourman.2012.12.007.

Bastan, M., Khorshid-Doust, R.R., Sisi, S.D. and Ahmadvand, A. (2018), "Sustainable development of agriculture: a system dynamics model”, Kybernetes, Vol. 47 No. 1, doi: 10.1108/K-01-2017-0003.

Bontkes, T.S. and van Keulen, H. (2003), "Modelling the dynamics of agricultural development at farm and regional level”, Agricultural Systems, Vol. 76 No. 1, pp. 379-396, doi: 10.1016/S0308-521X(02) 00128-2.

Boorsma, A. (1990), Possibilities for Arable Farms in the Dutch Peat Soil District, Rijksuniversiteit.

Busby, G. and Rendle, S. (2000), "The transition from tourism on farms to farm tourism", Tourism Management, Vol. 21 No. 6, pp. 635-642, doi: 10.1016/S0261-5177(00)00011-X.

Cassel, S.H. and Pettersson, K. (2015), "Performing gender and rurality in Swedish farm tourism", Scandinavian Journal of Hospitality and Tourism, Vol. 15 Nos 1-2, pp. 138-151, doi: 10.1080/ 15022250.2015.1005333.

Chamber of Agriculture and Forestry of Slovenia (2019), "Analiza stanja dopolnilnih Dejavnosti”, available at: https://www.kgzs.si/uploads/dokumenti/strokovna_gradiva/analiza_dopolnilnih_ dejavnosti.pdf (accessed 10 January 2020).

Costanza, R. (1997), Frontiers in Ecological Economics: Transdisciplinary Essays by Robert Costanza, Edward Elgar Publishing.

Crumley, B. (2010), "How to save rural France", Time Magazine, Vol. 2, pp. 12-19. 
$\mathrm{K}$ 51,13

Cunha, C., Kastenholz, E. and Carneiro, M.J. (2018), "Lifestyle entrepreneurs: the case of rural tourism", in Entrepreneurship and Structural Change in Dynamic Territories, Springer, Cham, pp. 175-188, doi: 10.1007/978-3-319-76400-9_10.

De Rosa, M., McElwee, G. and Smith, R. (2019), "Farm diversification strategies in response to rural policy: a case from rural Italy", Land Use Policy, Vol. 81, pp. 291-301, doi: 10.1016/j.landusepol. 2018.11.006.

Dent, J.B., Edwards-Jones, G. and McGregor, M.J. (1995), "Simulation of ecological, social and economic factors in agricultural systems", Agricultural Systems, Vol. 49 No. 4, pp. 337-351, doi: 10.1016/ 0308-521X(95)00029-5.

Dernoi, L.A. (1983), "Farm tourism in Europe”, Tourism Management, Vol. 4 No. 3, pp. 155-166, doi: 10. 1016/0261-5177(83)90060-2.

Decree on subsidiary activities on farms. Official Gazette of the Republic of Slovenia, number 57/15 and $36 / 18$.

Dubois, C., Cawley, M. and Schmitz, S. (2017), "The tourist on the farm: a 'muddled' image”, Tourism Management, Vol. 59, pp. 298-311, doi: 10.1016/j.tourman.2016.08.016.

Embacher, H. (1994), "Marketing for agri-tourism in Austria: strategy and realisation in a highly developed tourist destination”, Journal of Sustainable Tourism, Vol. 2 Nos 1-2, pp. 61-76, doi: 10.1080/09669589409510684.

Federal Ministry for Agriculture and Forestry, Environment and Water (2015), “Grüner Bericht 2015”, available at: http://www.gruenerbericht.at/cm4/jdownload/send/2-gr-bericht-terreich/1523gb2015-pdf (accessed 20 August 2019).

Forrester, J.W. (1994), "System dynamics, systems thinking, and soft OR”, System Dynamics Review, Vol. 10 Nos 2-3, pp. 245-256, doi: 10.1002/sdr.4260100211.

Gannon, A. (1994), "Rural tourism as a factor in rural community economic development for economies in transition”, Journal of Sustainable Tourism, Vol. 2 Nos 1-2, pp. 51-60, doi: 10.1080/ 09669589409510683.

Gunn, C.A. (1988), Tourism Planning, 2nd ed., Taylor \& Francis.

Hill, B. (2018), Farm Incomes, Wealth and Agricultural Policy, Routledge.

Hines, J. (2017), Molecules of Structure: Building Blocks for System Dynamics Models, MIT Sloan School of Management, Cambridge.

Huang, W.J., Beeco, J.A., Hallo, J.C. and Norman, W.C. (2016), "Bundling attractions for rural tourism development", Journal of Sustainable Tourism, Vol. 24 No. 10, pp. 1387-1402, doi: 10.1080/ 09669582.2015.1115510.

IPES-Food (2020), "COVID-19 and the crisis in food systems: symptoms, causes, and potential solutions", Communique.

Jakulin, T.J. (2016), "System dynamics models as decision-making tools in agritourism", Agricultura, Vol. 13 Nos 1-2, pp. 5-10.

Johnson, T.G., Bryden, J.M., Refsgaard, K. and Alva Lizarraga, S. (2008), “A system dynamics model of agriculture and rural development: the topmard core model”, No. 692-2016-47419, doi: 10.22004/ ag.econ.6497.

Kerma, S., Lampič, B. and Podmenik, D. (2014), "Tourism as a supplementary activity on organic farms in the Primorska region, Slovenia”, Academica Turistica, Vol. 7 No. 2, pp. 101-112.

Kheiri, J. and Nasihatkon, B. (2016), "The effects of rural tourism on sustainable livelihoods (case study: Lavij rural, Iran)", Modern Applied Science, Vol. 10 No. 10, pp. 10-22, doi: 10.5539/mas.v10n10p10.

Król, K. (2019), "Forgotten agritourism: abandoned websites in the promotion of rural tourism in Poland", Journal of Hospitality and Tourism Technology, Vol. 10 No. 10, doi: 10.1108/JHTT-092018-0092. 
Lazanski, T.J. and Kljajić, M. (2006), "Systems approach to complex systems modelling with special regards to tourism”, Kybernetes: The International Journal of Systems and Cybernetics, Vol. 35 Nos 7-8, pp. 1048-1058, doi: 10.1108/03684920610684779.

Mai, T. and Smith, C. (2018), "Scenario-based planning for tourism development using system dynamic modelling: a case study of Cat Ba Island, Vietnam", Tourism Management, Vol. 68, pp. 336-354, doi: 10.1016/j.tourman.2018.04.005.

Marsat, J.B., Menegazzi, P., Monin, C., Bonniot, A. and Bouchaud, M. (2013), "Designing a regional policy of agrotourism-the case of Auvergne region (France)", European Countryside, Vol. 5 No. 4, pp. 308-321, doi: 10.2478/euco-2013-0020.

Martins, L.F., Gan, Y. and Ferreira-Lopes, A. (2017), "An empirical analysis of the influence of macroeconomic determinants on world tourism demand", Tourism Management, Vol. 61, pp. 248-260, doi: 10.1016/j.tourman.2017.01.008.

Ministry of Agriculture, Forestry and Food (2019), Amounts of Income from Ancillary Activities on the Farm, Internal material, MKGP - Ministry of Agriculture, Forestry and Food, Ljubljana.

National Institute of Statistics (2015), "Le aziende agrituristiche in Italia-Anno 2014", Statistiche Report 27th November 2015. Rome, available at: http:/www.istat.it/it/files/2015/11/Aziendeagrituristiche.pdf?title $=$ Aziende + agrituristiche $+\mathrm{in}+\mathrm{Italia}+-+27 \% 2 \mathrm{Fnov} \% 2 \mathrm{~F} 2015+-$ +Testo+integrale.pdf (accessed 20 August 2019).

Oliva, R. (1995), A Vensim ${ }^{\circledR}$ Module to Calculate Summary Statistics for Historical Fit, Harvard Business School, Boston.

Pažek, K. and Rozman, Č. (2010), "Tourist farm service quality assessment”, Revija za Geografijo, Vol. 5 No. 2, pp. 149-158.

Podnar, K. and Golob, U. (2001), The Problem of Advertorial and Commercialisation of Slovene Press, Pristop, Ljubljana.

Potočnik Slavič, I. (2010), Endogeni razvojni Potenciali Slovenskega Podeželja, Znanstvena založba Filozofske fakultete Univerze v Ljubljani, Ljubljana, doi: 10.4312/9789610600381.

Pulighe, G. and Lupia, F. (2020), "Food first: COVID-19 outbreak and cities lockdown a booster for a wider vision on urban agriculture", Sustainability, Vol. 12 No. 12, p. 5012, doi: 10.3390/su12125012.

Rahmandad, H. and Sterman, J.D. (2012), Reporting Guidelines for Simulation-Based Research in Social Sciences, Wiley-Blackwell Publishers.

Romão, J., Kourtit, K., Neuts, B. and Nijkamp, P. (2018), “The smart city as a common place for tourists and residents: a structural analysis of the determinants of urban attractiveness", Cities, Vol. 78, pp. 67-75, doi: 10.1016/j.cities.2017.11.007.

Rossi, R. (2020), "European Union food system", available at: https://www.europarl.europa.eu/ RegData/etudes/BRIE/2020/652058/EPRS_BRI(2020)652058_EN.pdf (accessed 05 May 2021).

Rozman, Č., Pažek, K., Kljajić, M., Bavec, M., Turk, J., Bavec, F. and Škraba, A. (2013), "The dynamic simulation of organic farming development scenarios-A case study in Slovenia", Computers and Electronics in Agriculture, Vol. 96, pp. 163-172, doi: 10.1016/j.compag.2013.05.005.

Rubiah, S. and Elamin, E.A. (2021), Build-back-better from COVID-19 with the Adoption of Sustainability Standards in Food Systems, United Nations.

Sedarati, P., Santos, S. and Pintassilgo, P. (2019), "System dynamics in tourism planning and development", Tourism Planning and Development, Vol. 16 No. 3, pp. 256-280, doi: 10.1080/ 21568316.2018.1436586.

Sedarati, P. (2015), System Dynamics in Tourism: A Systematic Literature Review, [Doctoral dissertation], University of Algarve, Faculty of Economics.

Senge, P.M. and Forrester, J.W. (1980), "Tests for building confidence in system dynamics models", System Dynamics, TIMS Studies in Management Sciences, Vol. 14, pp. 209-228.

Sharpley, R. (2002), "Rural tourism and the challenge of tourism diversification: the case of Cyprus", Tourism Management, Vol. 23 No. 3, pp. 233-244, doi: 10.1016/S0261-5177(01)00078-4. 
$\mathrm{K}$

51,13

Sinclair-Maragh, G. and Gursoy, D. (2016), "A conceptual model of residents' support for tourism development in developing countries", Tourism Planning and Development, Vol. 13 No. 1, pp. 1-22, doi: 10.1080/21568316.2015.1047531.

Statistical Office of the Republic of Slovenia (2018), "Accommodation, tourist arrivals and overnight stays by tourist establishments, Slovenia, 2018-final data", available at: https://pxweb.stat.si/ SiStatDb/pxweb/s1/20_Ekonomsko/20_Ekonomsko_21_gostinstvo_turizem_01_nastanitev_ 01_21644_nastanitev_mesecno/2164430S.px/table/tableViewLayout2/ (accessed 29 August 2019).

Statistical Office of the Republic of Slovenia (2020a), "Agricultural holdings, general overview, Slovenia, by years”, available at: https:/pxweb.stat.si/SiStatDb/pxweb/s1/30_Okolje/30_ Okolje_15_kmetijstvo_ribistvo_03_kmetijska_gospod_00_15560_splosno/1556001S.px/ chart/chartViewLine/ (accessed 15 June 2020).

Statistical Office of the Republic of Slovenia (2020b), "Tourist arrivals and overnight stays by tourist accommodation establishments, measures and year", available at: https:/pxweb.stat.si/SiStatDb/ pxweb/s1/20_Ekonomsko/20_Ekonomsko_21_gostinstvo_turizem_01_nastanitev_02_21645_ nastanitev_letno/2164518S.px/table/tableViewLayout1/ (accessed 15 June 2020).

Statistical Office of the Republic of Slovenia (2020c), "Gainful activities on family farms by gainful activity, measures and year", available at: https://pxweb.stat.si/SiStatDb/pxweb/s1/ REPOZITORI_SLO/REPOZITORI_SLO/1516106S.px/table/tableViewLayout2/ (accessed 16 June 2020).

Sterman, J.D. (1984), "Appropriate summary statistics for evaluating the historical fit of system dynamics models", Dynamica, Vol. 10 No. 2, pp. 51-66.

Sterman, J.D. (2000), Business Dynamics: System Thinking and Modeling for a Complex World, Irwin McGraw-Hill, Boston.

StMELF - Programmbestimmungen für Erzeugnisse der Land- und Ernährungswirtschaft. Bayerisches Staatsministerium für Ernährung, Landwirtschaft und Forsten (2015), "Urlaub auf dem Bauernhof", available at: http://www.agrarbericht-2014.bayern.de/landwirtschaftlaendliche-entwicklung/urlaub-auf-dem-bauernhof.html (accessed 20 April 2020).

Su, M.M., Wall, G., Wang, Y. and Jin, M. (2019), "Livelihood sustainability in a rural tourism destination-Hetu Town, Anhui Province, China”, Tourism Management, Vol. 71, pp. 272-281, doi: 10.1016/j.tourman.2018.10.019.

Tew, C. and Barbieri, C. (2012), "The perceived benefits of agritourism: the provider's perspective", Tourism Management, Vol. 33 No. 1, pp. 215-224, doi: 10.1016/j.tourman.2011.02.005.

Tzouvelekas, V., Pantzios, C.J. and Fotopoulos, C. (2001), "Economic efficiency in organic farming: evidence from cotton farms in Viotia, Greece", Journal of Agricultural and Applied Economics, Vol. 33 No. 1, pp. 35-48, doi: 10.22004/ag.econ.15288.

Williams, A.M. and Shaw, G. (Eds) (1998), in Tourism and Economic Development: European Experience, Wiley.

World Travel and Tourism Council (2019), "Economic impact reports", available at: https:/wttc.org/ Research/Economic-Impact (accessed 16 March 2020).

Zanoli, R., Gambelli, D. and Vairo, D. (2012), "Scenarios of the organic food market in Europe", Food Policy, Vol. 37, pp. 41-57, doi: 10.1016/j.foodpol.2011.10.003.

Zasada, I. and Piorr, A. (2015), "The role of local framework conditions for the adoption of rural development policy: an example of diversification, tourism development and village renewal in Brandenburg, Germany”, Ecological Indicators, Vol. 59, pp. 82-93, doi: 10.1016/j.ecolind.2015. 02.002 .

Žibert, M., Rozman, Č., Prevolšek, B. and Škraba, A. (2019), "The system dynamics model for diversification of agricultural holdings into farm tourism", in Zadnik Stirn, L., Kljajić Borštar, M., Žerovnik, J., Drobne, S. and Povh, J. (Eds), SOR'19 Proceedings, Slovenian Society Informatika, Section for Operational Research, Ljubljana, pp. 34-38. 
Žibert, M., Rozman, Č., Škraba, A. and Prevolšek, B. (2020), "A system dynamics approach to decisionmaking tools in farm tourism development", Business Systems Research: International Journal of the Society for Advancing Innovation and Research in Economy, Vol. 11 No. 2, pp. 132-148, doi: 10.2478/bsrj-2020-0020.

Developing a diversification strategy

\section{Appendix:}

\section{Model Equations}

Model time Units: years

Numerical methods

Differential Equations Method: Euler

Algebraic Equations Method: Modified Newton

Mixed Equations Method: RK45 + Newton

Absolute accuracy: 1.00E-05

Time accuracy: 1.00E-05

Relative accuracy: 1.00E-05

Fixed time step: 0.001

Stock: diversedFarms

Description: Farms that have diversified.

Initial value 778

Unit: farm

Description Farms that have diversified.

Dynamic Variable: farms ThinkingAboutTransition

Formula: diversedFarms*contactsToThink

Unit: Farm

Description Number of farms, that think about transition due to information spread.

Dynamic Variable: ratioPotentialVsDiversed

Formula: potentialFarmsForDiversification/diversedFarms

Unit: dmnl

Description Ratio of potential vs diversified farms.

Flow: closingFarms

Formula: ratioOfClosing*impactOfDiversificationRateOnClosing(ratioPotentialVsDiversed)

*potentialFarmsForDiversification*((1-variable)*0.6)

Unit: farm/year

Description Farms that close each year. This could be diminished, if more diversed farms would be present with higher income.

Stock: potentialFarmsForDiversification

Unit: farm

Description Farms that are suitable for transition, acreage between 10ha and 15ha.

Dynamic Variable: totalNoOfFarms

Formula: potentialFarmsForDiversification + diversedFarms

Unit: farm

Description Total number of farms.

Dynamic Variable: concentrationOfPotentialFarms

Formula: potentialFarmsForDiversification/totalNoOfFarms

Unit: dmnl

Description Concentration of potential farms. This will diminish over time since less and less potential farms for diversification will be present.

Dynamic Variable: averageIncomePerFarm

Formula: (touristDepartures*averageIncomePerDay*averageStayTimeInDays)/diversedFarms

Dynamic Variable: averageStay Time

Formula: averageStayTimeInDays/noOfDaysInYear

Flow: touristDepartures

Formula: numberOfTourists/averageStayTime

Dynamic Variable: noOfTouristsPerDiversedFarm 
$\mathrm{K}$

51,13

56
Formula: numberOfTourists/diversedFarms

Unit: people/farm

Description Number of tourists per diversified farm.

Stock: numberOfTourists

Unit: people

Description Number of tourists on touristic farms.

Dynamic Variable: numberOfContacts

Formula: concentrationOfPotentialFarms*farmsThinkingAboutTransition

Unit: farms/year

Description Number of farms that decided to make a transition.

Dynamic Variable: noOfDecided

Formula: numberOfContacts*transitionFactor

Unit: farm/year

Description Number of farms that decided to make a transition.

Dynamic Variable: transitionFactor

Formula: normalTransitionFactor*(atractivenesDueToSubsidies(percentageOfSubsidies)

*weigthSubsidies + attractivenessDueToIncome*weigthIncome)*variable

Flow: transition

Description: Transition from conventional farm to diversified.

Unit: farm/year

Description Transition from conventional farm to diversified.

Dynamic Variable: attractivenessDueToIncome

Formula: attractivenessDueToIncomeF(averageIncomePerFarm)

Flow: touristArrivals

Formula: touristGrowthTrend(time))*impactOnArrivals(noOfTouristsPerDiversedFarm)

Flow: transition

Description: Transition from conventional farm to diversified.

Formula: noOfDecided

Unit: farm/year

Description Transition from conventional farm to diversified.

Flow: closingFarms

Formula: ratioOfClosing*impactOfDiversificationRateOnClosing(ratioPotentialVsDiversed) *potentialFarmsForDiversification*((1-variable)*0.6)

Unit: farm/year

Description Farms that close each year. This could be diminished, if more diversed farms would be present with higher income.

Flow: touristArrivals

Formula: touristGrowthTrend(time())*impactOnArrivals(noOfTouristsPerDiversedFarm)

Flow: touristDepartures

Formula: numberOfTourists/averageStayTime

\section{Corresponding author}

Črtomir Rozman can be contacted at: crt.rozman@um.si

For instructions on how to order reprints of this article, please visit our website:

www.emeraldgrouppublishing.com/licensing/reprints.htm

Or contact us for further details: permissions@emeraldinsight.com 